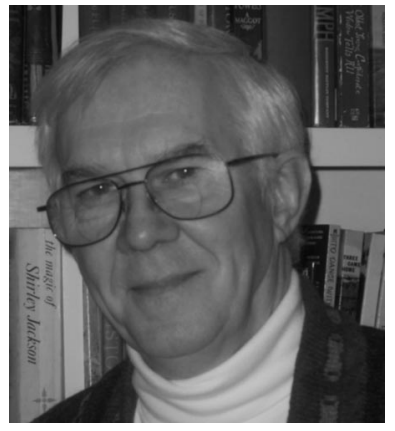

\section{e-First, Publishing in Real Time}

There are some exciting new changes for Optical Engineering in 2005. Beginning in January, all SPIE journals will start publishing accepted papers online as soon as the author proof corrections have been made and the editorial staff has approved the article for publication. The primary objective of this "article-at-a-time" publishing is to shorten the time between acceptance and publication. Following the current rules of TechSpell, this new feature has been dubbed "e-First."

In e-First publishing, the online table of contents for an issue is generated as a dynamic partial table of contents that changes as papers are added to the issue. Once the closing date of the issue is reached, the table of contents is completed and the print version of the journal is produced.

The purpose of this process is to speed up the publishing process. Previously, papers ready for publication had to be held until all the papers to be included in an issue were ready. So some completed papers were not available for weeks. Next month, readers who have access to the online version of Optical Engineering will be able to read some papers several weeks earlier than in the past. Along with publishing full color in the online version of journal papers, e-First is another way that SPIE is exploiting the increasing capabilities of electronic publishing.

One wrinkle in real-time publishing that had to be ironed out before it could be put in place was establishing a new scheme for assigning page numbers to papers on the fly. In the pagination scheme for this issue, the first page number continues from the last page of the last month's issue. This will be replaced with a scheme that uses a unique six-digit number for each article in both the online and print versions of the journal. This will permit the article to be fully cited as soon as it is published online. An author wishing to cite the paper would not have to wait for the table of contents for the issue to be completed. This article numbering scheme will permit the journal to organize and maintain section headings and to sequence papers within the table of contents without regard for the order in which the papers are published.
The six-digit article number (XXYYZZ) has three elements: the first two digits (XX) designate the month of the issue (01 through 12), the second two digits (YY) designate the subject/topic area or type of paper (e.g., editorial, letter, paper, erratum), and the last two digits $(\mathrm{ZZ})$ designate the sequence within that particular section. For example, an Optical Engineering paper with an article number 023214 that is published in 2005 (Volume 44) would be interpreted as follows: The issue number "02" means it appears in the February 2005 issue; the second set of two digits " 32 " designates the topic section heading (e.g., Imaging Systems); "14", indicates that the article is the 14th paper in the Imaging Systems topical section. With e-First, paper number 14 may very well be published before papers 01 through 13 , but it will appear in its proper sequence as the online issue builds and in the resulting print journal.

Citations for papers published in Optical Engineering beginning with the January 2005 issue should be formatted using the volume and six-digit article code, rather than volume and page number; for example, Opt. Eng. 44, 023214 (2005) refers to the example paper described above.

Each paper will start on page one and the pages will be numbered consecutively with a hyphen following the article number, for example, 023214-1, 023214-2, 0232143 ... In contrast to earlier conventions, the page numbers are not part of a paper citation; the six-digit article number will be sufficient. The hyphen and subsequent digit indicating a page should only be included to cite specific sections within a paper.

As part of the change to e-First publishing, the publication timeline for the print journal will also be adjusted. The print issues will appear at the end of each month, rather than at its beginning, and the cover date will reflect the month that the articles in that issue appeared online, rather than the date of print publication. For example, the August 2005 issue will contain articles published online from 1 August through 31 August, and the issue will be printed and mailed in mid-September. This gradual readjustment in the publication schedule will be fully in place by the August 2005 issue. 
Access to e-First papers will be through the online version of Optical Engineering. In addition to SPIE's other three journals (the Journal of Biomedical Optics; the Journal of Electronic Imaging; and the Journal of Microlithography, Microfabrication, and Microsystems), Optical Engineering can be accessed through the SPIE Digital Library at www.spiedl.org. Currently all issues of Optical Engineering published since 1998 are available online. The archives going back to 1990 will be added soon. Anyone can search and browse the tables of contents and abstracts of all of these journals online; however, a subscription is required to download full-text papers. We encourage readers to use this resource.

While we think there is still great value in receiving and reading our journal in printed form, there are unique features to an online journal-color, searchability, access to back issues, and now e-First-that provide a compel- ling argument for selecting the online journal over the print journal.

\section{Donald C. O'Shea \\ Editor}

\section{Publisher's Note:}

The annual Author and Subject indexes that have previously been printed in the last issue of each volume have been discontinued, due to the availability of metadata searching in the online version of this journal. SPIE journal articles published from 1998 to the current issue can be searched online using the SPIE Digital Library (http:// www.spiedl.org). A subscription is not required to use the search and browse features or to view tables of contents and abstracts. Downloading of full-text digital papers is available only to subscribers. 